(2) Open Access Full Text Article

\title{
Increased concentration of hyaluronan in tears after soaking contact lenses in Biotrue multipurpose solution
}

This article was published in the following Dove Press journal:

Clinical Ophthalmology

7 October 2016

Number of times this article has been viewed

\section{Catherine A Scheuer \\ Marjorie J Rah \\ William T Reindel}

Vision Care, Bausch \& Lomb Incorporated, Rochester, NY, USA
Correspondence: Marjorie J Rah

Vision Care, Bausch \& Lomb Incorporated, 1400 North Goodman Street Rochester, NY |4609, USA

Tel + I 5854 II36397

Email marjorie.rah@bausch.com
Purpose: This study was conducted to determine 1) the concentration of hyaluronan (HA) in the tear films of contact lens (CL) wearers versus non-CL wearers and 2) whether HA sorbed from Biotrue, an HA-containing multipurpose solution (MPS), onto senofilcon A lenses affects the concentration of HA in tears after 2 hours of wear.

Patients and methods: Tears of habitual CL wearers and non-CL wearers were collected on Schirmer strips at baseline and after 2 hours of wear of senofilcon A CLs that had first been either rinsed with Sensitive Eyes Saline or soaked in Biotrue MPS for 14 hours. HA concentrations were measured by enzyme-linked immunosorbent assay (ELISA) and adjusted for sample volumes. Results: No difference in baseline concentrations of HA in tears was found between CL wearers and non-CL wearers $(P=0.07)$, nor between males and females $(P=0.06)$. However, age was significantly negatively associated with HA concentration $(P<0.01)$, and mostly, CL wear contributed to a significant association $(P<0.01)$. Among saline-rinsed $C L$ wearers, no change in HA concentration in tears was observed after 2 hours of wear $(P=0.38)$. By contrast, a significant increase in HA concentration was observed in the tears from eyes that had worn CLs soaked in Biotrue MPS when compared to baseline $(P=0.01)$ or to saline-rinsed control $(P=0.03)$.

Conclusion: 1) In this study population, no difference in baseline concentration of HA was observed between CL wearers and non-CL wearers, and 2) after 2 hours of wear of senofilcon A lenses that were soaked in Biotrue MPS, HA concentrations in the tear films of CL wearers increased.

Keywords: contact lens, dry eye, hyaluronan, MPS

\section{Introduction}

The glycosaminoglycan hyaluronan (HA) is a biological polymer of repeating glucuronic acid and N-acetyl-D-glucosamine disaccharide units present throughout the human body. ${ }^{1}$ Its molecular structure is highly conserved in mammals; the molecule is recognized by various cell surface receptors that signal for subsequent biological events, particularly during development and at sites of wound healing. ${ }^{2}$ In addition, $\mathrm{HA}$ is rich in chemical moieties that bind water. ${ }^{3}$ Its distribution is site specific, but in many structures, it is colocated with CD44, a cell surface receptor for both HA and fibronectin. ${ }^{4,5}$

\section{$\mathrm{HA}$ in the human body}

HA is abundant in extracellular matrix and pericellular matrix, with approximately half present in the skin and the rest present in other anatomical locations such as synovial fluid, umbilical cord, and the eye. ${ }^{6}$ Supplemental HA and its derivatives are 
a clinical and commercial success in dermal, ${ }^{7}$ orthopedic, ${ }^{7}$ and ophthalmic ${ }^{8}$ products.

\section{$\mathrm{HA}$ in the eye}

HA is present in many ocular structures including lacrimal tissue, conjunctival epithelium, conjunctival stroma, corneal epithelium, corneal endothelium, stroma of the peripheral cornea, keratocytes, and extracellular matrix, as well as in most biological fluids including tears. ${ }^{9}$ Among its reported functions is the promotion of corneal epithelial migration and wound healing, ${ }^{4,5,10}$ possibly by the stimulation

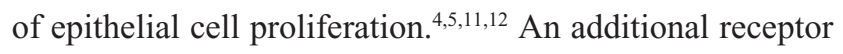
called the receptor for HA-mediated motility is implicated in cellular uptake of HA. ${ }^{13}$ Table 1 summarizes numerous reports that describe the advantages of HA to the tear film and the corneal surface.

The hydrophilic and hygroscopic characteristics of HA are well described. ${ }^{14,15}$ Its presence in the corneal surface promotes water retention and increases wettability. ${ }^{16-19}$ Although histological studies implicate corneal stromal cells as a possible source of HA in the eye, ${ }^{4}$ its presence in natural tears ${ }^{9,20}$ suggests that tear-born HA might sorb on corneal epithelium through the CD44 receptor and stabilize the preocular tear film. ${ }^{5}$ However, the "normal" concentration of HA in natural tears remains unclear, with relatively low concentrations but large ranges (from undetectable to $840.6 \times 10^{3} \mathrm{ng} / \mathrm{mL}$ ) reported in normal eyes and similarly low concentrations but smaller ranges $\left(1.4-40 \times 10^{3} \mathrm{ng} / \mathrm{mL}\right)$ reported in eyes of contact lens (CL) wearers and dry eye patients. ${ }^{21}$

\section{Supplementation of tear HA}

Ophthalmic uses of HA, including as a tear supplement, are well reviewed. ${ }^{8,22,23}$ Numerous studies report that eye drops

Table I Functions of hyaluronan in the human eye

\begin{tabular}{l} 
Retains water $(\sim 1,000 \times \text { by weight })^{14,15}$ \\
Thickens the tear film ${ }^{27}$ \\
Increases tear film breakup time ${ }^{16-18}$ \\
Stabilizes the tear film ${ }^{5,16,24,52,53}$ \\
Decreases tear evaporation rate ${ }^{54}$ \\
Maintains corneal wettability and prevents corneal dehydration ${ }^{19,45,55,56}$ \\
Lubricates the ocular surface during blinking and movement ${ }^{9,55}$ \\
Decreases blink frequency \\
Alleviates symptoms of dry eye \\
Stabilizes ocular surface epithelial barrier \\
Promotes corneal epithelial migration \\
Prevents free-radical-mediated, oxidative cellular damage \\
Decreases ocular inflammation \\
Ameliorates toxic effects of ophthalmic solution preservatives \\
Promotes wound healing and epithelial repair \\
\hline
\end{tabular}

containing HA are effective at alleviating the symptoms of dry eye. ${ }^{17,18,24,25}$ As HA has a unique combination of mucoadhesive and hygroscopic characteristics, it can both bind water and adhere to the ocular surface.

HA can also be applied to the eyes of CL wearers through eye drops. Gurny et al reported zero-order clearance of HA for the first 195s after instillation of HA solutions and the persistence of half or more of the instilled $\mathrm{HA}$ in the precorneal area after 20 minutes, depending upon solution concentration. ${ }^{26}$ Kaya et al reported that a commercial HA-containing eye drop increased tear film thickness (in the absence of CL) for as long as 30 minutes. ${ }^{27}$ Similarly, Garcia-Lázaro et $\mathrm{al}^{28}$ reported that a commercial HA-containing CL rewetting drop (Blink Contacts ${ }^{\circledR}$; AMO, Santa Ana, CA, USA) ${ }^{29}$ increased tear volume for at least 10-20 minutes after instillation and possibly longer. These observations suggest that CLs could be used as a vehicle to deliver HA to the tear film and the eye, thus providing the benefits of HA supplementation to $\mathrm{CL}$ wearers. Table 2 summarizes the purported advantages of HA supplementation.

In addition to its use in eye drops and lens rewetting drops, HA is also used as a conditioning agent in certain CL multipurpose solutions (MPSs). These include Biotrue MPS (Bausch \& Lomb Incorporated, Rochester, NY, USA) and some others that are used in the rest of the world. Biotrue MPS is a sterile, isotonic solution containing 1.4 MDa HA $(0.01 \%, w / w),{ }^{30}$ surfactants, and disinfectants. ${ }^{31}$ It was reported that high-molecular-weight HA in this MPS readily sorbs on a variety of both poly(2-hydroxyethyl methacrylate)based and silicone hydrogel CL during lens storage and then elutes into artificial tear fluid in vitro over a 20-hour period. ${ }^{22,32}$ In addition, it increased the wettability of many CL materials. ${ }^{33}$ Biotrue MPS clinically performs well, as both patients and practitioners express a high degree of satisfaction based upon both objective and subjective criteria, particularly end of day comfort. ${ }^{34}$

Considering the reports on the advantages of HA in natural tears, eye drops to treat dry eye, and CL rewetting drops,

Table 2 Advantages of hyaluronan supplementation

\begin{tabular}{l} 
Increased tear fluid stability ${ }^{5,16,24,52,53}$ \\
Increased corneal wettability $19,45,55,56$ \\
Increased tear film breakup time t6-18 $^{16}$ \\
Decreased tear evaporation rate ${ }^{54}$ \\
Decreased protein and bacterial adhesion ${ }^{23}$ \\
Decreased corneal staining ${ }^{24}$ \\
Alleviation of symptoms of dry eye e $^{16-18,24,25,58}$ \\
\hline
\end{tabular}


as well as literature reporting the elution of HA from lenses soaked in HA-containing solutions, it was hypothesized that lenses stored overnight in Biotrue MPS would deliver HA to a lens wearer's tear film during wear. The objective of this study was to determine whether HA sorbed from Biotrue MPS on a silicone hydrogel CL and subsequently eluted into the eye would remain present within the tear film after 2 hours of lens wear.

\section{Materials and methods Clinical study design}

This randomized, single-masked, contralateral study was conducted in accordance with the tenets outlined by the Declaration of Helsinki and was approved by the Southwest Independent Review Board. Written informed consent was obtained from each of the 25 subjects matched for age and sex (12 habitual CL wearers and 13 non-CL wearers). This study was registered with the Clinical Trials identifier NCT01317030.

\section{Elution of HA from contact lenses into the tear film during wear}

In the first phase of the study, tears of both CL wearers and non-CL wearers were collected on each of three consecutive visits, no more than 3 days apart, and both tear volume and HA concentration were measured as described below. In the second phase of the study, the CL wearers on each of three additional consecutive visits, no more than 3 days apart, wore a senofilcon A (ACUVUE ${ }^{\circledR}$ OASYS $^{\circledR}$; Vistakon ${ }^{\circledR}$, Jacksonville, FL, USA) control lens rinsed with Sensitive Eyes Saline (Bausch \& Lomb) in one eye and a senofilcon A test lens that had been soaked in Biotrue MPS for 14 hours in the other eye. The clinician randomly assigned the eye which should receive the test lens for each patient at each visit. Tears were collected on Schirmer strips, and tear volumes were recorded at baseline and again after 2 hours of wearing the CLs. Schirmer strips were stored frozen until the analysis.

\section{Measurement of HA concentration in collected tears}

HA was extracted by wetting thawed Schirmer strips with 0.1 mL Hanks' Balanced Salt Solution (Product Code 14025; GIBCO, Waltham, MA, USA), vortexing, and centrifuging. HA concentrations of the extracts were measured by using HA enzyme-linked immunosorbent assay (ELISA) (Product Code K-1200; Echelon Biosciences, Salt Lake City, UT, USA) and adjusted for collected tear volumes.

\section{Statistical analysis}

In the first phase of the study, baseline HA concentrations and tear volumes were measured in each eye on each of three separate visits of 12 habitual CL wearers and 13 non-CL wearers. Respective average values were calculated for each eye from the three visits of each patient, and differences between CL wearers and non-CL wearers were tested for significance by Wilcoxon rank sum test.

Each measured concentration value (expressed in $\mathrm{ng} / \mathrm{mL}$ ) was transformed to its natural logarithmic value to closer approximate normal distribution, and a mixed effects model was used to account for correlations obtained due to multiple observations of the same subjects. The continuous variable (subject age) was analyzed by using a linear regression mixed effects model with $\ln [\mathrm{HA}]$ as the outcome variable. The categorical variable (sex) was analyzed by using a repeated measures analysis of variance model with $\ln [\mathrm{HA}]$ as the outcome variable. A repeated measures analysis of variance model was used to evaluate differences in HA concentrations. Comparisons with $P$-values $\leq 0.05$ were considered statistically different.

In the second phase of the study, 12 habitual CL wearers wore a CL rinsed with saline in one eye and a CL soaked in Biotrue MPS in the other. HA concentrations were measured in tears collected from each eye on each of three separate visits and transformed to their natural logarithmic values for statistical comparison.

\section{Results}

In total, 25 subjects matched for age and sex (12 habitual CL wearers and 13 non-CL wearers) participated in this randomized, single-masked, contralateral study.

\section{Baseline tear volumes and HA concentrations}

Baseline HA concentrations measured from the tears of test and control subjects varied among subjects in the range from undetectable to $3.02 \times 10^{3} \mathrm{ng} / \mathrm{mL}$. Tear volumes collected ranged from 1 to $35 \mu \mathrm{L}$ with means of $21.0 \pm 11.6 \mu \mathrm{L}$ from $\mathrm{CL}$ wearers and $19.5 \pm 11.3 \mu \mathrm{L}$ from non-CL wearers. No significant differences between CL wearers and non-CL wearers were observed in either tear volume $(P=0.57)$ or HA concentration $(P=0.07)$ as summarized in Table 3 . Sex was not significantly associated with HA concentration for CL wearers $(P=0.09)$, non-CL wearers $(P=0.23)$, or the population as a whole $(P=0.06$; all probabilities based upon natural logarithm-transformed data) as summarized in Table 4. However, age was negatively associated with baseline HA 
Table 3 Baseline HA tear volumes and concentrations in CL wearers and non-CL wearers

\begin{tabular}{|c|c|c|c|c|c|c|c|}
\hline \multirow[t]{2}{*}{ Variable } & \multicolumn{3}{|c|}{ CL wearers } & \multicolumn{3}{|c|}{$\begin{array}{l}\text { Non-CL } \\
\text { wearers }\end{array}$} & \multirow{2}{*}{$\begin{array}{l}\text { P-value } \\
\text { (Wilcoxon } \\
\text { rank sum test) }\end{array}$} \\
\hline & $\mathbf{n}$ & Mean & SD & $\mathbf{n}$ & Mean & $\overline{S D}$ & \\
\hline $\begin{array}{l}\text { HA concentration } \\
(\mathrm{ng} / \mathrm{mL})\end{array}$ & 24 & 207 & 295 & 26 & 115 & 159 & 0.07 \\
\hline Tear volume $(\mu \mathrm{L})$ & & 21.0 & 11.6 & & 19.5 & 11.3 & 0.57 \\
\hline
\end{tabular}

Abbreviations: $\mathrm{CL}$, contact lens; $\mathrm{HA}$, hyaluronan; $\mathrm{SD}$, standard deviation.

tear concentration (ie, the older the subject, the lower the HA concentration, $P<0.01$ ), with $\mathrm{CL}$ wear contributing mostly to significant association $(P<0.01$ based upon natural logarithm-transformed data) as summarized in Table 5.

\section{Tear HA concentrations after 2 hours of lens wear}

Table 6 shows natural logarithm-transformed HA concentrations in tears from all CL-wearing subjects. HA concentration did not differ before and after wear of saline-rinsed control lenses (Figure 1; $P=0.38$ based upon natural logarithm-transformed data) nor between Biotrue MPS baseline and saline baseline groups (Table $6 ; P=0.87$ based upon natural logarithm-transformed data). A significant increase in HA concentration was observed in tears from eyes of the patients who had worn CL first soaked in Biotrue MPS when compared to baseline $(P=0.01)$ and saline-rinsed control CL $(P=0.03)$.

\section{Discussion}

HA is present in various ocular structures with locationspecific distribution patterns. ${ }^{5}$ In the corneal epithelium, it is colocated with its CD44 receptor. It was reported that in the cornea HA promotes epithelial migration and wound healing ${ }^{10,11}$ and protects the cornea from the toxic effects of ophthalmic solution preservatives, ${ }^{19,35,36}$ and in natural tears, it helps to stabilize the tear film. ${ }^{5}$

While the concentration of HA in natural tears is reported in literature, there is no consensus as to what constitutes normal concentration, in part due to differences in measurement techniques between different studies. Berry et al studied 18 normal subjects aged 22-42 years and 15 dry eye sufferers aged $32-90$ years. In this small population, HA concentration in tears from the "normal" eyes ranged from undetectable to $840.6 \times 10^{3} \mathrm{ng} / \mathrm{mL}$, in dry eye sufferers from undetectable to $83.9 \times 10^{3} \mathrm{ng} / \mathrm{mL}$, and in CL wearers from 1.4 to $40 \times 10^{3} \mathrm{ng} / \mathrm{mL}$, with very low values in most samples, that is, high levels were outliers. ${ }^{21}$ They found no change in concentration during the use of artificial tears. By contrast, Frescura et al measured an HA concentration range of $0.012-1.9 \times 10^{3} \mathrm{ng} / \mathrm{mL}$ in tears after washing eyes of some subjects with saline prior to tear collection, with a trend toward higher concentrations in females than in males. ${ }^{20}$ Fukuda et al reported a similarly large HA concentration range of $0.036-1.565 \times 10^{3} \mathrm{ng} / \mathrm{mL}$ in tears. ${ }^{37}$ Although the variations between studies may reflect the different collection techniques, the causes of abnormally high HA concentrations in tears are poorly understood.

In the present study, baseline HA concentrations ranging from undetectable to $3.02 \times 10^{3} \mathrm{ng} / \mathrm{mL}$ were measured, which are in the order of similar values reported by others..$^{20,37}$ Neither CL wear $(P=0.07$; Table 3$)$ nor sex $(P=0.06$; Table 4$)$ affected baseline HA concentration. However, a trend toward higher HA concentration in CL wearers (Table 3) was observed. In contrast to Frescura et al, ${ }^{20}$ a trend toward lower HA concentrations in females than in males (Table 4) was observed in the present study. The high inherent variability in HA concentration measurement complicates interpretation of statistical testing. The sizable differences in mean HA concentration between sample groups (207 vs $115 \mathrm{ng} / \mathrm{mL}$ for CL wearers vs non-CL wearers, respectively; $224 \mathrm{vs} 88 \mathrm{ng} / \mathrm{mL}$ for males vs females, respectively; $304 \mathrm{vs} 111 \mathrm{ng} / \mathrm{mL}$ for male vs female CL wearers, respectively; and $156 \mathrm{vs} 66 \mathrm{ng} / \mathrm{mL}$ for male vs female non-CL wearers, respectively) were not statistically different, but this may reflect the small sample size and large inherent standard deviation in the measurements (295 vs $159 \mathrm{ng} / \mathrm{mL}$ for $\mathrm{CL}$

Table 4 Association of sex with baseline HA tear concentration

\begin{tabular}{|c|c|c|c|c|c|c|c|}
\hline Variable & Group & Level & $\begin{array}{l}\text { Mean [HA] } \\
(\mathrm{ng} / \mathrm{mL})\end{array}$ & SD & $\begin{array}{l}\text { Mean In[HA] } \\
(\mathrm{ng} / \mathrm{mL})\end{array}$ & SD & $P$-value \\
\hline \multirow[t]{6}{*}{ Sex } & All & $\mathrm{F}$ & 88 & 83 & 4.08 & 0.157 & 0.06 \\
\hline & & M & 224 & 307 & 4.50 & 0.151 & \\
\hline & $\mathrm{CL}$ wearers & $\mathrm{F}$ & 111 & 103 & 4.25 & 0.232 & 0.09 \\
\hline & & $M$ & 304 & 389 & 4.81 & 0.232 & \\
\hline & Non-CL wearers & $\mathrm{F}$ & 66 & 52 & 3.91 & 0.190 & 0.23 \\
\hline & & $M$ & 156 & 206 & 4.23 & 0.176 & \\
\hline
\end{tabular}

Abbreviations: $\mathrm{CL}$, contact lens; $F$, female; HA, hyaluronan; $M$, male; SD, standard deviation. 
Table 5 Association of age with baseline HA tear concentration

\begin{tabular}{lllll}
\hline Variable & Group & Slope & Standard error & P-value \\
\hline Age & All & -0.041 & 0.012 & $<0.01$ \\
& CL wearers & -0.044 & 0.015 & $<0.01$ \\
& Non-CL & -0.037 & 0.019 & 0.06 \\
& wearers & & & \\
\hline
\end{tabular}

Abbreviations: $\mathrm{CL}$, contact lens; $\mathrm{HA}$, hyaluronan; $\mathrm{SD}$, standard deviation.

wearers and non-CL wearers, respectively; 307 vs $83 \mathrm{ng} / \mathrm{mL}$ for males and females, respectively; $389 \mathrm{vs} 103 \mathrm{ng} / \mathrm{mL}$ for male and female CL wearers, respectively; and 206 vs $52 \mathrm{ng} / \mathrm{mL}$ for male and female non-CL wearers, respectively) relative to the measured values themselves rather than the lack of true difference between mean values.

It is also found that age is negatively associated with baseline HA tear concentration in both $\mathrm{CL}$ wearers and the overall study population (both $P<0.01$; Table 5). It is interesting to note that during aging, changes in the tear film lipid layer reduce tear film stability, ${ }^{38}$ tear volume, ${ }^{39}$ tear stability, ${ }^{40}$ and tear film breakup time,${ }^{41}$ regardless of sex, although some studies found greater effect in females than in males..$^{38}$ These phenomena are consistent with decreased HA concentration in tears during aging.

The physical, chemical, and biochemical characteristics of HA make it a nearly ideal component in supplemental tears. ${ }^{9}$ Its mucoadhesive characteristic allows the molecule to stick to solids with a relatively long residence time. ${ }^{42}$ Tavazzi et al showed that HA readily sorbs on a Food and Drug Administration Group 1 silicone hydrogel (Safilens), filling the pores and associating with the surface. ${ }^{43}$ Mochizuki et al reported that turnover of HA instilled on the naked eye was significantly less than the bulk aqueous flow rate, implying that HA remained on the ocular surface. ${ }^{44}$ Hydrophilic characteristics of HA lead to increased corneal hydration and wettability. ${ }^{45}$ In addition, it likely contributes to ocular health through its beneficial biochemical effects on ocular epithelium. ${ }^{4,5,10}$ These characteristics led to the development of a number of HA-containing products for various ophthalmic conditions and procedures, including artificial tears. ${ }^{8}$

Table 6 HA concentrations in the tears of CL wearers before and after wear of $\mathrm{CL}$ rinsed with saline or soaked in Biotrue MPS

\begin{tabular}{llllllll}
\hline Solution & Group & $\mathbf{n}$ & $\begin{array}{l}\text { Mean } \\
\text { [HA] } \\
(\mathbf{n g} / \mathbf{m L})\end{array}$ & $\begin{array}{l}\text { SD } \\
\text { Biotrue }\end{array}$ & $\begin{array}{l}\text { Mean } \\
\text { In[HA] } \\
\mathbf{( n g / m L )}\end{array}$ & SD & P-value \\
& Baseline & 12 & 147 & 117 & 4.50 & 0.98 & 0.01 \\
Saline & Treatment & 389 & 493 & 5.10 & 1.37 & \\
& Baseline & 267 & 401 & 4.56 & 1.27 & 0.38 \\
& Treatment & 158 & 213 & 4.34 & 1.09 & \\
\hline
\end{tabular}

Abbreviations: $\mathrm{CL}$, contact lens; $\mathrm{HA}$, hyaluronan; MPS, multipurpose solution.

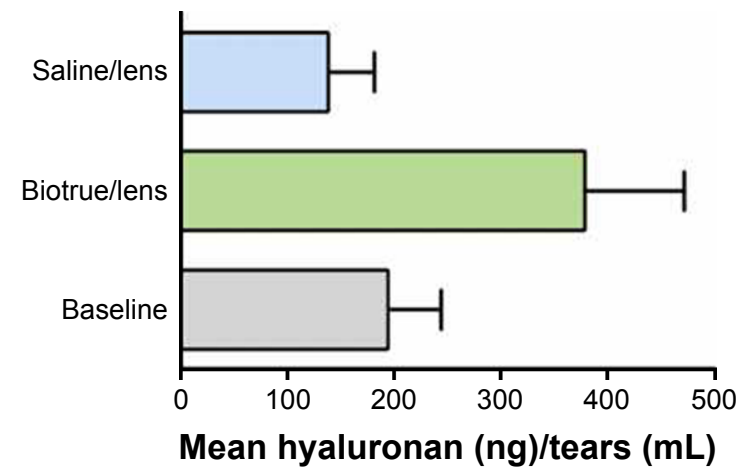

Figure I HA concentration (average + standard error, lower error bar omitted for clarity) in tears before and after 2 hours of wear of senofilcon A lenses that had been either rinsed with saline or soaked for 14 hours in Biotrue MPS.

Notes: HA concentrations were tested for significance using a mixed effects model after transformation to natural logarithmic values to closer approximate normal distribution. HA concentration after 2 hours of wear of the lens rinsed with saline was not different from baseline value $(P=0.38)$, whereas the concentration after wear of the lens soaked in Biotrue MPS was greater than baseline value $(P=0.009)$ or after wear of the lens rinsed with saline $(P=0.33)$.

Abbreviations: HA, hyaluronan; MPS, multipurpose solution.

HA-containing eye drops are successfully used to supplement tear film HA to alleviate the symptoms of dry eye. Johnson et al reported decreased ocular irritation and increased tear breakup time in patients with dry eye treated with eye drops containing $0.1 \%$ or $0.3 \%$ HA. ${ }^{17}$ Vogel et al found eye drops containing $0.18 \%$ HA effective at decreasing both objective and subjective symptoms of dry eye. ${ }^{25}$ Condon et al reported similar results for eye drops containing $0.1 \% \mathrm{HA}^{24}$ Saeed et al found HA-containing gels to be effective in decreasing dry eye symptoms, including foreign body sensation, itching, burning, watering, photophobia, and feeling of dryness. ${ }^{18}$

Similar to HA-containing drops for the treatment of dry eye, HA-containing rewetting drops are used to alleviate ocular dryness in CL wearers. ${ }^{28,29,46}$ However, although eye drops provide a large bolus of HA, the residence time of the HA in the tear film is relatively short compared with the daily period of CL wear. ${ }^{26}$

In order to address the limitations of HA delivery via eye drops, Van Beek et al proposed sorbing HA from dilute alcohol solution into CL materials capable of delivering either free HA of relatively high-molecular-weight or physically entrapped, cross-linked HA of relatively low-molecular-weight HA to the tear film and the eye. ${ }^{23}$ They reported first-order release of free $900 \mathrm{kDa}$ HA from poly(2-hydroxyethyl methacrylate)-based lenses, with half of the initially loaded HA eluted after 5 hours and $90 \%$ after 1-day incubation with phosphate-buffered saline. By contrast, both 35 and $169 \mathrm{kDa}$ cross-linked HA remained bound within the lens and did not elute. Ali and Byrne designed a lens material with enhanced affinity for 
HA based upon the formulation for commercial nelfilcon A lenses by carefully selecting acrylate and methacrylate lens monomers that mimic amino acids from the HA-binding site of CD 44. ${ }^{47}$ Poly(vinyl alcohol) macromer was first mixed with $1.2-\mathrm{kDa} \mathrm{HA}$ prior to the addition of functional monomers acrylamide, N-vinyl pyrrolidone, and 2-(diethylamino) ethyl methacrylate. The diffusion coefficient of HA through the hydrogel decreased by a factor of up to $3 \times$, depending upon the concentration and diversity of the functional monomers, resulting in half-order, controlled elution of HA $>24$ hours in vitro. Recently, Maulvi et al compared elution of HA from hydrogel lenses first soaked in HA solution to lenses with HA entrapped during lens fabrication. They reported that entrapment of HA at high concentration adversely affects transmittance and polymer swelling. ${ }^{48}$ At lower concentration, lens performance was acceptable, and the mean residence of HA in rabbit tear fluid was increased when compared with eye drops. Fagnola et al measured $2.0 \times 10^{3} \mathrm{ng} / \mathrm{mL}$ HA elution from a commercial Filcon 1B Hyaluronate Gel lens (Safe-Gel; Safilens s.r.1., Staranzano, Italy) ${ }^{49}$ after 5-day incubation with deionized water. ${ }^{50}$ Weeks et al reported 3-7 weeks of release of HA incorporated into lenses during synthesis, depending upon lens composition. ${ }^{51}$

Previously, elution of HA sorbed from Biotrue MPS onto nine different lens materials was measured in vitro and occurred continuously over the 20-hour time frame of the experiment. ${ }^{22,32}$ Thus, CLs soaked in Biotrue MPS overnight and then placed on the eye may potentially supplement tear film HA and provide the wearer with some of the advantages that are summarized in Table 2, possibly over the entire duration of daily lens wear. In the present clinical study, HA concentrations in the tears of test subjects were measured after 2 hours of wear of senofilcon A lenses that had been either rinsed with saline or soaked overnight in Biotrue MPS. Wearing CLs rinsed with saline did not affect HA concentration in tears $(267 \pm 401 \mathrm{ng} / \mathrm{mL}$ before vs $158 \pm 213 \mathrm{ng} / \mathrm{mL}$ after [average \pm standard deviation]; $P=0.38$ based upon natural log-transformed data), whereas wearing lenses soaked in Biotrue MPS resulted in higher concentration $(147 \pm 117 \mathrm{ng} / \mathrm{mL}$ before vs $389 \pm 493 \mathrm{ng} / \mathrm{mL}$ after; $P=0.01$ ) as shown in Table 6 . This likely indicates that HA from Biotrue MPS continuously elutes from the lens over at least the 2 hours of the experiment. This duration is superior to the reported transient increased HA volume in tears after instillation of HA-containing CL rewetting drops, ${ }^{29}$ which, although effective, must be used repeatedly throughout the day to achieve the same effect. Similarly, eye drops containing higher molecular weight HA or that include excipients to increase HA residence time on the lens might reduce the frequency of instillation of rewetting drops.

As was the case in preliminary baseline HA comparisons between males and females, CL-wearing and non-CL wearing, and young and old subjects (Tables 3-5), large differences in baseline HA concentration and relatively large standard deviations were observed in these comparison groups ( $147 \pm 117$ vs $267 \pm 401 \mathrm{ng} / \mathrm{mL}$ for saline-rinsed CL vs CL soaked in Biotrue, MPS respectively). This again reflects the poorly understood, large inherent variability in HA concentration in tears. Until the cause of individual variation in HA concentration is better understood and controlled, statistical evaluation of this parameter will remain less than ideal in future studies.

\section{Conclusion}

In a previous in vitro study, CLs continued to elute HA over a 20-hour time period when rinsed in vitro at the rate of tear film secretion..$^{22,32}$ The present clinical study demonstrated that HA persists in the tears of CL wearers after 2 hours of wear of senofilcon A CLs that had previously been soaked in high-molecular-weight HA-containing MPS. Further studies are required to determine over what duration of wear HA concentration in tears remains elevated above the baseline.

\section{Acknowledgment}

We wish to thank Stephanie Su-Brady for conducting the clinical study and Lening Zhang for assistance with statistical analysis.

\section{Disclosure}

All authors are employees of Bausch \& Lomb Incorporated, Rochester, NY, USA. The authors report no other conflicts of interest in this work.

\section{References}

1. Dumitriu S, ed. Polysaccharides: Structural Diversity and Functional Versatility. 2nd ed. New York: Marcel Dekker; 2004.

2. Price RD, Berry MG, Navsaria HA. Hyaluronic acid: the scientific and clinical evidence. J Plast Reconstr Aesthet Surg. 2007;60(10): 1110-1119.

3. Shanker RM, Ahmed I, Bourassa PA, Carola KV. An in-vitro technique for measuring contact angles on the corneal surface and its application to evaluate corneal wetting properties of water soluble polymers. Int $J$ Pharm. 1995;119(2):149-163.

4. Asari A, Morita M, Sekiguchi T, Okamura K, Horie K, Miyauchi S. Hyaluronan, CD44 and fibronectin in rabbit corneal epithelial wound healing. Jpn J Ophthalmol. 1996;40(1):18-25.

5. Lerner LE, Schwartz DM, Hwang DG, Howes EL, Stern R. Hyaluronan and CD44 in the human cornea and limbal conjunctiva. Exp Eye Res. 1998; 67(4):481-484.

6. Kogan G, Soltés L, Stern R, Gemeiner P. Hyaluronic acid: a natural biopolymer with a broad range of biomedical and industrial applications. Biotechnol Lett. 2007;29(1):17-25. 
7. Fakhari A, Berkland C. Applications and emerging trends of hyaluronic acid in tissue engineering, as a dermal filler and in osteoarthritis treatment. Acta Biomater. 2013;9(7):7081-7092.

8. Rah MJ. A review of hyaluronan and its ophthalmic applications. Optometry. 2011;82(1):38-43.

9. Aragona P. Chapter 24. Hyaluronan in the treatment of ocular surface disorders. In: Garg HG, Hales CA, editors. Chemistry and Biology of Hyaluronan. Oxford: Elsevier Ltd; 2004:529-551.

10. Nishida T, Nakamura M, Mishima H, Otori T. Hyaluronan stimulates corneal epithelial migration. Exp Eye Res. 1991;53(6):753-758.

11. Inoue $\mathrm{M}$, Katakami $\mathrm{C}$. The effect of hyaluronic acid on corneal epithelial cell proliferation. Invest Ophthalmol Vis Sci. 1993;34(7): 2313-2315.

12. Yokoi N, Komuro A, Nishida K, Kinoshita S. Effectiveness of hyaluronan on corneal epithelial barrier function in dry eye. Br J Ophthalmol. 1997;81(7):533-536.

13. Contreras-Ruiz L, de la Fuente M, Párraga JE, et al. Intracellular trafficking of hyaluronic acid-chitosan oligomer-based nanoparticles in cultured human ocular surface cells. Mol Vis. 2011;17:279-290.

14. Laurent TC, Fraser JRE. Hyaluronan. FASEB J. 1992;6(7):2397-2404.

15. Bray BA. The role of hyaluronan in the pulmonary alveolus. $J$ Theor Biol. 2001;210(1):121-130.

16. Mengher LS, Pandher KS, Bron AJ, Davey CC. Effect of sodium hyaluronate $(0.1 \%)$ on break-up time (NIBUT) in patients with dry eyes. Br J Ophthalmol. 1986;70(6):422-427.

17. Johnson ME, Murphy PJ, Boulton M. Effectiveness of sodium hyaluronate eyedrops in the treatment of dry eye. Graef Arch Clin Exp Ophthalmol. 2006;244(1):109-112.

18. Saeed N, Qazi Z, H Butt N, Siddiqi A, Maheshwary N, Athar Khan M. Effectiveness of sodium hyaluronate eye gel in patients with dry eye disease: a multi-centre, open label, uncontrolled study. Pak J Med Sci. 2013;29(4):1055-1058.

19. Wysenbeek YS, Loya N, Ben Sira I, Ophir I, Ben Shaul Y. The effect of sodium hyaluronate on the corneal epithelium. An ultrastructural study. Invest Ophthalmol Vis Sci. 1988;29(2):194-199.

20. Frescura M, Berry M, Corfield A, Carrington S, Easty DL. Evidence of hyaluronan in human tears and secretions of conjunctival cultures. Biochem Soc Trans. 1994;22:228S.

21. Berry M, Pastis WK, Ellingham RB, Frost L, Corfield AP, Easty DL. Hyaluronan in dry eye and contact lens wearers. Adv Exp Med Biol. 1998;438:785-790.

22. Scheuer CA, Fridman KM, Barniak VL, Burke SE, Venkatesh S. Retention of conditioning agent hyaluronan on hydrogel contact lenses. Cont Lens Anterior Eye. 2010;33(Suppl 1):S2-S6.

23. Van Beek M, Jones L, Sheardown H. Hyaluronic acid containing hydrogels for the reduction of protein adsorption. Biomaterials. 2008; 29(7):780-789.

24. Condon PI, McEwen CG, Wright M, Mackintosh G, Prescott RJ, McDonald C. Double blind, randomised, placebo controlled, crossover multicentre study to determine the efficacy of a $0.1 \%(\mathrm{w} / \mathrm{v})$ sodium hyaluronate solution (Fermavisc) in the treatment of dry eye syndrome. Br J Ophthalmol. 1999;83(10):1121-1124.

25. Vogel R, Crockett RS, Oden N, Laliberte TW, Molina L; Sodium Hyaluronate Ophthalmic Solution Study Group. Demonstration of efficacy in the treatment of dry eye disease with $0.18 \%$ sodium hyaluronate ophthalmic solution (vismed, rejena). Am J Ophthalmol. 2010;149(4):594-601.

26. Gurny R, Ryser JE, Tabatabay C, Martenet M, Edman P, Camber O. Precorneal residence time in humans of sodium hyaluronate as measured by gamma scintigraphy. Graefes Arch Clin Exp Ophthalmol. 1990;228(6):510-512.

27. Kaya S, Schmidl D, Schmetterer L, et al. Effect of hyaluronic acid on tear film thickness as assessed with ultra-high resolution optical coherence tomography. Acta Ophthalmol. 2015;93(5):439-443.

28. Garcia-Lázaro S, Madrid-Costa D, Ferrer-Blasco T, Montés-Micó R, Cerviño A. OCT for assessing artificial tears effectiveness in contact lens wearers. Optom Vis Sci. 2012;89(1):E62-E937.
29. FDA 510k Summary K032030. Blink ${ }^{\mathrm{TM}}$ CL Lubricant Eye Drops; September 25, 2003. Available from: http://www.accessdata.fda.gov/ cdrh_docs/pdf3/k032030.pdf. Accessed August 24, 2016.

30. Liu XM, Harmon PS, Maziarz EP, Rah MJ, Merchea MM. Comparative studies of hyaluronan in marketed ophthalmic products. Optom Vis Sci. 2014;91(1):32-38.

31. FDA 510(k) Summary K083757. Bausch \& Lomb BPZ02 MultiPurpose Solution; November 18, 2009. Available from: https://www.accessdata. fda.gov/cdrh_docs/pdf8/K083757.pdf. Accessed August 24, 2016.

32. Scheuer CA, Doty K, Liranso T, Burke SE. Wetting agent retention and release from hydrogel and silicone hydrogel contact lenses. Invest Ophthalmol Vis Sci. 2011;52(14):6487.

33. Fagehi RA, Tomlinson A, Manahilov V. Comparative study of soft contact lens wetting in vitro after storage in Biotrue MPS. Cont Lens Anterior Eye. 2012;35(Suppl 1):e21.

34. Reindel W, Cairns G, Merchea M. Assessment of patient and practitioner satisfaction with Biotrue ${ }^{\mathrm{TM}}$ multi-purpose solution for contact lenses. Cont Lens Anterior Eye. 2010;33(Suppl 1):S12-S17.

35. Ye J, Zhang $\mathrm{H}, \mathrm{Wu} \mathrm{H}$, et al. Cytoprotective effect of hyaluronic acid and hydroxypropyl methylcellulose against DNA damage induced by thimerosal in Chang conjunctival cells. Graefes Arch Clin Exp Ophthalmol. 2012;250(10):1459-1466.

36. Yu F, Liu X, Zhong Y, et al. Sodium hyaluronate decreases ocular surface toxicity induced by benzalkonium chloride-preserved latanoprost: an in vivo study. Invest Ophthalmol Vis Sci. 2013;54(5): 3385-3393.

37. Fukuda M, Miyamoto Y, Miyara Y, Mishima H, Ottori T. Hyaluronic acid concentration in human tear fluids. Invest Ophthalmol Vis Sci. 1996; 37(Suppl):S848.

38. Maïssa C, Guillon M. Tear film dynamics and lipid layer characteristics effect of age and gender. Cont Lens Anterior Eye. 2010;33(4):176-182.

39. Mathers WD, Lane JA, Zimmerman MB. Tear film changes associated with normal aging. Cornea. 1996;15(3):229-234.

40. Patel S, Boyd KE, Burns J. Age, stability of the precorneal tear film and the refractive index of tears. Cont Lens Anterior Eye. 2000;23(2): 44-47.

41. Ozdemir M, Temizdemir H. Age- and gender-related tear function changes in normal population. Eye (Lond). 2010;24(1):79-83.

42. Snibson GR, Greaves JL, Soper NDW, Prydals JI, Wilson CG, Bron AJ. Precorneal residence times of sodium hyaluronate solutions studied by quantitative gamma scintigraphy. Eye (Lond). 1990;4: 594-602.

43. Tavazzi S, Tonveronachi M, Fagnola M, et al. Wear effects on microscopic morphology and hyaluronan uptake in siloxane-hydrogel contact lenses. J Biomed Mater Res B Appl Biomater. 2015;103(5): 1092-1098.

44. Mochizuki H, Yamada M, Hato S, Nishida T. Fluorophotometric measurement of the precorneal residence time of topically applied hyaluronic acid. Br J Ophthalmol. 2008;92(1):108-111.

45. Nakamura M, Hikida M, Nakano T, Ito S, Hamano T, Kinoshita S. Characterization of water retentive properties of hyaluronan. Cornea. 1993;12: $433-436$.

46. FDA 510k Summary K042176. AQuify Lens Comfort Drops, November 3, 2004. Available from: https://www.accessdata.fda.gov/cdrh_docs/ pdf4/K042176.pdf. Accessed August 24, 2016.

47. Ali M, Byrne ME. Controlled release of high molecular weight hyaluronic acid from molecularly imprinted hydrogel contact lenses. Pharm Res. 2009;26(3):714-726.

48. Maulvi FA, Soni TG, Shah DO. Extended release of hyaluronic acid from hydrogel contact lenses for dry eye syndrome. J Biomater Sci Polym Ed. 2015;26(15):1035-1050.

49. Filippo A, inventor; Safilens SRL, assignee. Contact lens, method for producing same, and pack for storage and maintenance of a contact lens. United States patent US 7726809. 2010 June 1.

50. Fagnola M, Pagani MP, Maffioletti S, Tavazzi S, Papagni A. Hyaluronic acid in hydrophilic contact lenses: spectroscopic investigation of the content and release in solution. Cont Lens Anterior Eye. 2009;32(3):108-112. 
51. Weeks A, Subbaraman LN, Jones L, Sheardown H. Physical entrapment of hyaluronic acid during synthesis results in extended release from model hydrogel and silicone hydrogel contact lens materials. Eye Contact Lens. 2013;39(2):179-185.

52. Hamano T, Horimoto K, Lee M, Komemushi S. Sodium hyaluronate eye drops enhance tear film stability. Jpn J Ophthalmol. 1996;40(1):62-65.

53. Lee HS, Ji YS, Yoon KC. Efficacy of hypotonic $0.18 \%$ sodium hyaluronate eye drops in patients with dry eye disease. Cornea. 2014; 33(9):946-951.

54. McCann LC, Tomlinson A, Pearce EI, Papa V. Effectiveness of artificial tears in the management of evaporative dry eye. Cornea. 2012;31(1):1-5.

55. Choy EP, Cho P, Benzie IF, Choy CK. Investigation of corneal effect of different types of artificial tears in a simulated dry eye condition using a novel porcine dry eye model (pDEM). Cornea. 2006;25(10): 1200-1204.
56. Zheng X, Goto T, Shiraishi A, Ohashi Y. In vitro efficacy of ocular surface lubricants against dehydration. Cornea. 2013;32(9):1260-1264.

57. Acosta MC, Gallar J, Belmonte C. The influence of eye solutions on blinking and ocular comfort at rest and during work at video display terminals. Exp Eye Res. 1999;68(6):663-669.

58. Aragona P, Papa V, Micali A, Santocono M, Milazzo G. Long term treatment with sodium hyaluronate-containing artificial tear reduces ocular surface damage in patients with dry eye. Br J Ophthalmol. 2002;86(2): 181-184.

59. Camillieri G, Nastasi A, Gulino P, Bucolo C, Drago F. Effects of hyaluronan on free radical formation, corneal endothelium damage, and inflammation parameters after phacoemulsification in rabbits. $J$ Ocul Pharmacol Ther. 2004;20(2):151-157.

60. Oh HJ, Li Z, Park SH, Yoon KC. Effect of hypotonic $0.18 \%$ sodium hyaluronate eyedrops on inflammation of the ocular surface in experimental dry eye. J Ocul Pharmacol Ther. 2014;30(7):533-542.
Clinical Ophthalmology

\section{Publish your work in this journal}

Clinical Ophthalmology is an international, peer-reviewed journal covering all subspecialties within ophthalmology. Key topics include: Optometry; Visual science; Pharmacology and drug therapy in eye diseases; Basic Sciences; Primary and Secondary eye care; Patient Safety and Quality of Care Improvements. This journal is indexed on

\section{Dovepress}

PubMed Central and CAS, and is the official journal of The Society of Clinical Ophthalmology (SCO). The manuscript management system is completely online and includes a very quick and fair peer-review system, which is all easy to use. Visit http://www.dovepress.com/ testimonials.php to read real quotes from published authors. 